COSTA LV; BENTES JLS; LOPES MTG; ALVES SRM; VIANA JÚNIOR JM. 2015. Caracterização de acessos de pimentas do Amazonas. Horticultura Brasileira 33: 290-298. DOI: http://dx.doi.org/10.1590/S0102-053620150000300003

\title{
Caracterização de acessos de pimentas do Amazonas
}

\author{
Lucifrancy V Costa; Jânia LS Bentes; Maria TG Lopes; Silfran RM Alves; Januário M Viana Júnior \\ Universidade Federal do Amazonas, (UFAM-FCA), Manaus-AM, Brasil; lucifrancy@yahoo.com.br; jlbentes@ufam.edu.br; mtglopes@
} ufam.edu.br; silfranrogerio@yahoo.com.br; januario.macedo@yahoo.com.br

\section{RESUMO}

No Brasil é encontrada ampla variabilidade de pimentas do gênero Capsicum sendo a Amazônia um importante centro de diversidade. Informações a respeito da diversidade em coleção de germoplasma servem, entre outros objetivos, para dar suporte aos programas de melhoramento de espécies cultivadas. O presente trabalho teve como objetivos caracterizar morfologicamente e estimar a diversidade genética entre 40 acessos de pimentas coletadas no Amazonas, pertencentes à coleção da Universidade Federal do Amazonas. Foram utilizados descritores morfológicos recomendados pelo IPGRI (International Plant Genetic Resources Institute) para o gênero Capsicum e análise sensorial para pungência e aroma. Utilizando 17 descritores, identificados como essenciais, foi calculada a similaridade genética entre os acessos por meio do coeficiente de similaridade geral de Gower. Para o agrupamento dos acessos foi utilizado o método hierárquico das médias das distâncias UPGMA (Unweighted Pair-Group Method Using an Arithmetic Average) e a representação gráfica da similaridade entre eles feita pelo método de Análise de Coordenadas Principais (PCO). Três espécies foram identificadas, sendo 35 de $C$. chinense um de $C$. baccatum e quatro acessos de $C$. frutescens. Houve variabilidade fenotípica principalmente nas características de frutos que mostraram diferenças quanto ao tamanho, formato, coloração e pungência. Foram identificadas duas pimenteiras do morfotipo murupi, duas dedo de moça, quatro malagueta, sete olho de peixe, 13 pimentas de cheiro e 12 pimentas curabiá. As análises de agrupamento e dispersão gráfica foram concordantes em agrupar os acessos com pequena distância genética. Os acessos estudados apresentaram ampla variabilidade entre e dentro das espécies identificadas.

Palavras chave: Capsicum, germoplasma, diversidade.

\section{ABSTRACT}

\section{Morphological characterization of Amazon pepper accessions}

In Brazil wide variability is found in peppers of Capsicum genus and the Amazon region is an important center of diversity. Information about the diversity in collection is useful, among other aspects, to increase the efficiency of breeding studies of cultivated species. The present study aimed to characterize the morphology and estimate the genetic diversity of 40 Capsicum accessions from Universidade Federal do Amazonas germplasm collection. Morphological descriptors recommended by IPGRI (International Plant Genetic Resources Institute), for the Capsicum and sensory analysis for pungency and flavor were used to characterize the accessions. Seventeen descriptors, identified as essentials, were used to calculate the genetic similarity among accessions, considering the general similarity coefficient of Gower. The hierarchical method of the average of the distances UPGMA (Unweighted Pair-Group Method using an Arithmetic Average) and PCO (Principal Coordinates Analysis) were used to cluster the accessions. Three species were found comprising 35 accessions of $C$. chinense, one of $C$. baccatum and four $C$. frutescens. Phenotypic variation among accessions was observed mainly on fruit characteristics that showed differences in size, shape, color and pungency. Several chilli peppers morphotypes were identified: two accessions of murupi; two lady's finger; four from "malagueta"; seven from fisheye; 13 from smell pepper, and 12 curabiá. Cluster and dispersion graph analysis were concordant in clustering accessions with small genetic distance. The collection presents a wide variation among accessions.

Keywords: Capsicum, germplasm, diversity.

(Recebido para publicação em 26 de março de 2014; aceito em 19 de março de 2015) (Received on March 26, 2014; accepted on March 19, 2015)

$\mathrm{O}$ gênero Capsicum pode ser caracterizado pela ampla diversidade de pimentas e pimentões que tiveram sua origem nas regiões tropicais do continente americano e são consumidos por um quarto da população mundial, principalmente na forma de condimentos (Moreira et al., 2006). O gênero possui cerca de 30 espécies já identificadas (Moscone et al., 2007). Dentre estas espécies descritas, apenas cinco são amplamente utilizadas e cultivadas, destacando-se C. annuum, C. chinense, C. frutescens, C. pubescens e C. baccatum.

No Brasil ocorrem quatro espécies: C. annuum, C. chinense, $C$. frutescens e C. baccatum, predominando comercialmente a produção de pimentões (C. annuum). Em toda a Amazônia, o consumo de pimentas é muito comum (Luz, 2007) e representam importante mercado para a agricultura brasileira, incluindo o seu uso como matéria-prima para as indústrias alimentícia, farmacêutica e cosmética. Embora tenham alcançado posição de destaque na olericultura nacional, as informações sobre algumas espécies são escassas (Henz \& Ribeiro, 2008).

Informações a respeito da diversidade de uma coleção de germoplasma servem para aumentar a eficiência dos trabalhos de melhoramento de espécies 
cultivadas. A Amazônia é importante centro de diversidade do gênero Capsicum, em especial da espécie Capsicum chinense, considerada a mais brasileira entre as espécies domesticadas e com ampla variabilidade genética, principalmente para características de fruto (Ribeiro et al., 2008).

Para que esses recursos genéticos sejam utilizados de forma eficiente é fundamental o conhecimento e a organização dos bancos de germoplasma, permitindo a exploração da variabilidade genética para uso em programas de melhoramento visando disponibilizar para o plantio variedades com alta produtividade, qualidade de fruto e resistência a pragas e doenças, entre outras características (Carvalho et al., 2003). Ribeiro et al. (2008) relataram que as coleções de Capsicum existentes no Brasil necessitavam de enriquecimento, caracterização genética e organização dos dados para que pudessem efetivamente ser empregadas em programas de melhoramento.

Em Capsicum, estudos de diversidade das espécies têm sido realizados através de caracterizações agronômicas, morfológicas e moleculares (Toquica et al., 2003; Sudré et al., 2006; Buttow et al., 2010; Sudré et al., 2010, Rêgo et al., 2011). A caracterização morfológica permite diferenciar os acessos existentes na coleção através da obtenção programada e sistemática de dados baseada em descritores capazes de descrever os acessos existentes. Em geral, são considerados caracteres da folha, flor, fruto e semente. Segundo Rodriguez et al. (2005), a caracterização de germoplasma é um elo importante entre a conservação e utilização dos recursos genéticos vegetais de forma eficiente, para que variabilidade genética existente na região seja adequadamente estudada, preservada e utilizada em benefício da sociedade.

O presente trabalho teve como objetivo caracterizar morfologicamente e estimar a diversidade genética entre acessos de Capsicum da região Amazônica.

\section{MATERIAL E MÉTODOS}

O experimento foi conduzido no
Sítio Vale Verde no ramal da Capivara, Rod. BR-174 km 8 em Manaus-AM (02 54'49'S, 6002'55'O, altitude 42 m). O clima da região é do tipo "Afi", no esquema Köppen, com pluviosidade média anual de $2.400 \mathrm{~mm}$ (ocorrência de chuvas intensas de janeiro a maio) e temperatura média anual de $26^{\circ} \mathrm{C}$. O solo é um latossolo amarelo.

Foram avaliados 40 acessos de pimentas (Capsicum spp.) de diferentes procedências do estado do Amazonas (Tabela 1), pertencentes à coleção de Capsicum da Faculdade de Ciências Agrárias da Universidade Federal do Amazonas.

Os ensaios foram conduzidos no período de maio a setembro de 2010 . Os acessos foram semeados em bandejas de poliestireno expandido e transplantados para sacos de polietileno aos 20 dias após a germinação. Aos 45 dias, as mudas foram levadas ao campo e plantadas no espaçamento de 1,5x1,0 m, em delineamento experimental de blocos ao acaso com cinco plantas e três repetições num total de 15 plantas de cada acesso. Os tratos culturais recomendados para a cultura foram realizados de acordo com Filgueira (2007).

Para a caracterização dos acessos foram utilizados 56 descritores morfológicos definidos pelo IPGRI (International Plant Genetic Resources Institute) para o gênero Capsicum (IPGRI, 1995) e dois caracteres propostos por Luz (2007). Plântula: Cor do hipocótilo $(1=$ branco; $2=$ verde; $3=$ roxo $)$; Pubescência do hipocótilo ( $1=$ esparsa; $2=$ intermediária; $3=$ densa); Cor da folha cotiledonar $\{1=$ verde-clara; $2=$ verde; $3=$ verde-escura; $4=$ violeta clara; $5=$ violeta; $6=$ violeta-escura (roxa); $7=$ variegada; $8=$ amarela; $9=$ outra $\}$; Forma da folha cotiledonar $(1=$ deltóide; 2= ovada; $3=$ lanceolada; 4= elongada-deltóide). Planta e caule: Cor do caule (haste) $(1=$ verde; $2=$ verde com estrias violeta; $3=$ violeta); Presença de antocianina nodal (planta toda, adulta) $\{1=$ verde; $3=$ violeta-claro; $5=$ violeta; $7=$ violeta escuro (roxo) $\}$; Forma do caule (haste) $(1=$ cilíndrico; $2=$ anguloso; $3=$ chato); Pubescência do caule (planta adulta, excluindo-se os dois primeiros nós antes da copa) e, Densidade da ramificação e, Densidade da folhagem média de 5 plantas maduras $(3=$ esparsa; $5=$ intermediária; $7=$ densa); Altura da planta $(\mathrm{cm})$, plantas com frutos amadurecendo $(1=<25 ; 2=25-45 ; 3=$ 45-65; 4=66-85; 5=>85); Hábito de crescimento da planta $\{3=$ prostrado; 5= intermediário (compacto); 7= ereto; 9= outro ; Comprimento do dossel $(\mathrm{cm})$ $(1=$ até $80 ; 2=80-120 ; 3=120-160 ; 4=$ $>160$ ); Comprimento da haste (altura do caule) $(\mathrm{cm})(1=$ até $15 ; 2=15-30 ; 3=$ 30-50; 4=>50); Diâmetro da haste $(\mathrm{cm})$ $(1=$ até $1 ; 2=1-2 ; 3=2-3 ; 4=>3)$; Brotação abaixo da primeira bifurcação (1= ausente; $3=$ esparsa; 5= intermediária). Folhas: Cor da folha $\{1=$ amarela; $2=$ verde-clara; $3=$ verde; $4=$ verde-escura; $5=$ violeta-clara; $6=$ violeta $($ roxa $) ; 7=$ mesclada; $8=$ verde com antocianina $\}$; Forma da folha $(1=$ deltóide; $2=$ ovalada; $3=$ lanceolada); Margem da lâmina ( $1=$ inteira; $2=$ ondulada; $3=$ ciliada $)$; Pubescência da folha $(3=$ esparsa; $5=$ intermediária; $7=$ densa); Comprimento da folha madura $(\mathrm{cm})(1=$ até $5 ; 2=$ $>5-10 ; 3=>10-15 ; 4=>15)$; Largura da folha madura, parte mais larga $(\mathrm{cm})$ $(1=$ até $3 ; 2=>3-6 ; 3=>6-9 ; 4=>9)$. Flores: Dias para o florescimento $(1=$ até $30 ; 2=31-60 ; 3=61-90 ; 4=>90)$; Número de flores por axila ( $1=$ uma; $2=$ duas; $3=$ três ou mais; $4=$ muitas com entrenó curto; $5=$ uma e duas; $6=$ uma, duas e três; $7=$ duas e três; $8=$ duas, três e quatro); Posição da flor ( $3=$ pendente; $5=$ intermediária; $7=$ ereta; $9=$ todas; $11=$ intermediária e ereta; $13=$ intermediária e pendente); Cor da corola ( $1=$ branca; $2=$ amarelo clara; $3=$ amarela; 4= amarelo esverdeada; $5=$ outra); Forma da corola $(1=$ rotada; $2=$ campanulada; $3=$ intermediária); Comprimento da corola (cm) $(1=<1,5 ; 2=1,5-2,0 ; 3=>2,0)$; Cor da antera $\{1=$ branca; $2=$ amarelo clara; $3=$ azul clara; $4=$ azul; 5= violeta (roxa); 6= amarelo com mancha azul clara $\}$; Posição do estigma $\{3=$ inserto (abaixo das anteras); 5= mesmo nível; $7=$ excerto (acima das anteras); 9= mesmo nível e excerto; $11=$ inserto e mesmo nível; 13= inserto e excerto $\}$; Pigmentação do cálice e, Constrição anelar do cálice $(0=$ ausente; $1=$ presente); Margem do cálice ( $1=$ inteira; $2=$ intermediária; $3=$ dentada). Frutos: Dias para frutificação $(1=$ até $60 ; 2=61-90$; $3=91-120 ; 4=$ acima de 120); Manchas 
ou estrias de antocianina e, Pescoço na base do fruto e, Apêndice na ponta do fruto ( $0=$ ausente; $1=$ presente); Cor do fruto $\{1=$ branco; $2=$ amarelo; $3=$ verde; $4=$ laranja; $5=$ violeta; $6=$ violeta-escuro (roxo); 7= amarelo-esverdeado; 8= verde-amarelado; 9= branco-amarelado; $10=$ marrom; $11=$ três cores (especificar) $\}$; Posição dos frutos ( $3=$ pendente; $5=$ intermediária; $7=$ ereta; $9=$ todas; $11=$ pendente e intermediária; $13=$ pendente e ereta; 15 = intermediária e ereta); Duração da frutificação ou carregamento da planta (dias) $(1=$ até $150 ; 2=>150$ 180; $3=>180)$; Cor do fruto no estádio maduro ( $1=$ branco; $2=$ amarelo-limão; 3= amarelo-laranja pálido; 4= amarelo-laranja; 5= laranja pálido; 6= laranja; $7=$ vermelho-claro; $8=$ vermelho; $9=$ vermelho-escuro; $10=$ violeta; $11=$ marrom; $12=$ preto; 13= amarelo; $14=$ amarelo pálido; 15= salmão); Forma do fruto $\{1=$ alongado; $2=$ arredondado; $3=$ triangular; 4= campanulado; 5= retangular (em bloco) $\}$; Comprimento do fruto $(\mathrm{cm})(1=$ até $1 ; 2=>1-2 ; 3=>2-4$; $4=>4-8 ; 5=>8-12 ; 6=>12)$; Largura do fruto $(\mathrm{cm})(1=$ até $1 ; 2=>1-2,5 ; 3=$ $>2,5-5 ; 4=>5-8 ; 5=>8)$; Massa de fruto (g) $(1=$ até $1 ; 2=>1-2 ; 3=>2-4 ; 4=>4-$ $8 ; 5=>8-12 ; 6=>12)$; Comprimento do pedúnculo $(\mathrm{cm})(1=$ até $2 ; 2=>2-4$; $3=>4-6 ; 4=>6)$; Espessura da parede do fruto $(\mathrm{mm})(1=$ até $1 ; 2=>1-2 ; 3=$ $>2-3 ; 4=>3-4 ; 5=>4-5 ; 6=>5$ ); Ombro do fruto na inserção do pedicelo ( $1=$ agudo; $2=$ obtuso; $3=$ truncado; $4=$ cordato; $5=$ lobado); Formato da ponta do fruto $\{1=$ pontiagudo; $2=$ truncado (blunt); 3= afundado; 4= afundado com ponta\}; Corrugação na seção transversal do fruto $(3=$ levemente corrugado; $5=$ intermediário; $7=$ corrugado); Número de lóculos $(1 ; 2 ; 3 ; 4 ; 5)$; Superfície do fruto $(1=$ liso; $2=$ semi-rugoso; $3=$ rugoso; 4= liso com estrias; 5= semi-rugoso com estrias); Persistência do fruto maduro em relação ao pedicelo $(3=$ pouco persistente; $5=$ intermediário; $7=$ persistente); Comprimento da placenta $(1=<1 / 4$ do comprimento do fruto; $2=\mathrm{de}$ $1 / 4-1 / 2$ do comprimento do fruto; $3=>1 / 2$ do comprimento do fruto); Pungência (sensorial) $(1=$ doce; $2=$ pungência baixa; 3= pungência média; 4= pungência alta); Aroma ( $1=$ baixo; $2=$ médio; $3=$ alto). Sementes: Superfície da semente
(1= lisa; $2=$ rugosa; $3=$ corrugada $)$ Número de sementes por fruto $(1=<20 ; 2=$ 21-50;3=>51).

Para os descritores de planta foram avaliadas todas as plantas do experimento na fase reprodutiva, na primeira frutificação em fase de maturação intermediária. Para os descritores de folhas e flores, foram utilizadas duas amostras aleatórias de cada planta do experimento, cada amostra contendo duas folhas ou duas flores e para os descritores de frutos foi usada uma amostra aleatória de 30 frutos por acesso conforme recomendação de Alves (2009). Para a avaliação dos caracteres pungência e aroma foi aplicado um questionário para 30 avaliadores que realizaram a classificação dos frutos, conforme as classes descritas na Tabela 2. Cada avaliador analisou um fruto inteiro de cada acesso, totalizando 40 frutos por avaliador.

Os dados morfológicos foram analisados pelo programa MVSP (Multi-Variate Statistical Package v. 3.2). O agrupamento dos acessos foi feito pelo método UPGMA (Unweighted Pair-Group Method Using Arithmetic Average) e a representação gráfica da similaridade entre eles feita pelo método de Análise de Coordenadas Principais (PCO). A análise de divergência entre os acessos para os caracteres morfológicos analisados foi realizada após o agrupamento e a comparação dos diferentes valores obtidos a partir do complemento aritmético do índice de similaridade de acordo com Gower (1966).

\section{RESULTADOS E DISCUSSÃO}

Dos 56 descritores avaliados apenas 10 (cor hipocótilo, forma da folha, comprimento da corola, pigmentação do cálice, manchas ou estrias com antocianina nodal, comprimento do pedúnculo, apêndice na ponta do fruto, superfície da semente, tamanho da semente e cor da semente) não apresentaram variação. Os 40 acessos analisados foram identificados como pertencentes a três espécies: 36 acessos de C. chinense, um acesso de $C$. baccatum e três acessos de C. frutescens.

Houve variação de classes nos caracteres de flores, folhas, plantas e principalmente nos frutos (Tabela 2). A variação de classes e valores observados para os descritores demonstram a grande variabilidade genética existente entre os acessos estudados. Fonseca et al. (2008), em estudo similar com genótipos pungentes de $C$. chinense relatam grande variabilidade genética no germoplasma analisado e destacam o caráter cor na classificação dos frutos, tendo observado sete cores diferentes de frutos no estádio intermediário e nove cores em frutos maduros. Alves (2009) ao estudar genótipos de $C$. chinense, morfotipo pimenta de cheiro sem pungência, também encontrou grande variabilidade genética dentro desse morfotipo e descreveu cinco cores no estádio intermediário e sete cores em frutos maduros. Neitzke et al. (2010) caracterizaram pimentas ornamentais, compreendendo genótipos de C. annuum, C. baccatum, $C$. chinense e $C$. frutescens e encontraram variabilidade genética para 22 caracteres avaliados com maior variabilidade para comprimento do fruto.

Baseado no descritor formato do fruto foi possível identificar seis morfotipos, sendo: duas pimenteiras do morfotipo murupi; sete pimenteiras olho de peixe; 13 pimenteiras de cheiro e 12 pimenteiras curabiá; duas pimenteiras dedo de moça e quatro pimenteiras malaguetas. A distinção dos morfotipos por formato do fruto facilita a organização da coleção e permite o estudo da diversidade genética dentro dos morfotipos identificados (Fonseca et al., 2008). A maioria dos morfotipos pertence a $C$. chinense, sendo caracterizados como pimenta de cheiro, curabiá, murupi e olho de peixe. Grande parte dos acessos está distribuída nos morfotipos pimenta de cheiro e curabiá. Resultado similar foi encontrado por Fonseca et al. (2008), avaliando acessos de pimentas do alto Rio Negro, corroborando a afirmação de Carvalho (2003) de que a bacia amazônica representa o principal centro de diversidade de $C$. chinense. O resultado deste estudo permitiu constatar a ampla variabilidade genética existente dentro da espécie (Figura 1).

O morfotipo dedo de moça foi identificado em duas espécies, $C$. chinense e C. baccatum. Apesar de a literatura identificar o morfotipo dedo de moça 
Tabela 1. Acessos de Capsicum ssp. coletados no Amazonas e suas respectivas procedências (Capsicum spp. accessions collected in the Amazonas State and their origin). Manaus, UFAM, 2013.

\begin{tabular}{|c|c|c|c|}
\hline Acesso & Procedência & Nome popular & Espécie \\
\hline $\mathrm{BC} 01$ & Benjamim Constant & Pimenta de cheiro & C. chinense \\
\hline $\mathrm{BC} 05$ & Benjamim Constant & Pimenta de cheiro & C. chinense \\
\hline ВC06 & Benjamim Constant & Olho de peixe & C. chinense \\
\hline BC09 & Benjamim Constant & Pimenta de cheiro & C. chinense \\
\hline $\mathrm{BC} 10$ & Benjamim Constant & Olho de peixe & C. chinense \\
\hline BC11 & Benjamim Constant & Pimenta de cheiro & C. chinense \\
\hline $\mathrm{BC} 12$ & Benjamim Constant & Pimenta de cheiro & C. chinense \\
\hline $\mathrm{BC} 13$ & Benjamim Constant & Malaguetinha & C. frutescens \\
\hline $\mathrm{BC} 14$ & Benjamim Constant & Pimenta de cheiro & C. chinense \\
\hline $\mathrm{BC} 16$ & Benjamim Constant & Desconhecido & C. chinense \\
\hline MA03 & Manaus & Dedo de moça & C. baccatum \\
\hline MA13 & Manaus & Desconhecido & C. chinense \\
\hline MA18 & Manaus & Pimenta de cheiro & C. chinense \\
\hline MA19 & Manaus & Malagueta & C. chinense \\
\hline MA20 & Manaus & Desconhecido & C. chinense \\
\hline MA31 & Manaus & Murupizão & C. chinense \\
\hline MA33 & Manaus & Murupi & C. chinense \\
\hline MA34 & Manaus & Desconhecido & C. chinense \\
\hline MA35 & Manaus & Desconhecido & C. chinense \\
\hline MA36 & Manaus & Desconhecido & C. chinense \\
\hline MA37 & Manaus & Desconhecido & C. chinense \\
\hline MA39 & Manaus & Desconhecido & C. chinense \\
\hline MA43 & Manaus & Pimenta de cheiro & C. chinense \\
\hline MA46 & Manaus & Desconhecido & C. chinense \\
\hline ATN01 & Atalaia do Norte & Pimento de cheiro & C. chinense \\
\hline ATN02 & Atalaia do Norte & Desconhecido & C. chinense \\
\hline ATN04 & Atalaia do Norte & Desconhecido & C. chinense \\
\hline ATN05 & Atalaia do Norte & Olho de peixe & C. chinense \\
\hline LA01 & Lábrea & Olho de peixe & C. chinense \\
\hline LA02 & Lábrea & Olho de peixe & C. chinense \\
\hline IRB01 & Iranduba & Pimento de cheiro & C. chinense \\
\hline IRB02 & Iranduba & Desconhecido & C. chinense \\
\hline IRB03 & Iranduba & Desconhecido & C. chinense \\
\hline CDJ01 & Codajás & Desconhecido & C. chinense \\
\hline CDJ03 & Codajás & Desconhecido & C. chinense \\
\hline AP04 & Apuí & Desconhecido & C. chinense \\
\hline AN01 & Anori & Murupi & C. chinense \\
\hline MU05 & Maués & Malagueta & C. frutescens \\
\hline TBT01 & Tabatinga & Olho de peixe & C. chinense \\
\hline $\mathrm{CO} 01$ & Coari & Malagueta & C. frutescens \\
\hline
\end{tabular}

como pimenta da espécie $C$. baccatum, Fonseca et al. (2008) atribuíram esta denominação na coleção de $C$. chinense analisada em seu estudo, devido à semelhança dos frutos, não levando em consideração caracteres de flor. No presente trabalho, utilizou-se essa mesma denominação. $\mathrm{O}$ morfotipo malagueta
A partir da matriz de similaridade foi gerado o agrupamento pelo método UPGMA (Figura 2), considerando os morfotipos de pimenteiras e os locais de procedência dos acessos. Foi utilizado o ponto de corte de 0,75 , considerando-se a similaridade relativa como ponto de corte no dendrograma, formando-se oito grupos, primeiro (G1) e o segundo grupo (G2) foram compostos pelo morfotipo pimenta de cheiro diferindo apenas no formato dos frutos. Todos os acessos do grupo G1 e G2 são da espécie C. chinense. No G1 estão presentes os acessos IRB01, CDJ03, BC12, MA18 e $\mathrm{BC} 09$, caracterizados pelo formato campanulado e alongado e no G2 estão presentes os acessos ATN01, BC14, $\mathrm{BC} 11, \mathrm{BC} 05$ e $\mathrm{BC} 01$ cujos frutos têm formato redondo. Nestes dois grupos, as plantas se caracterizavam por ter caule verde, floração iniciada entre 61 e 90 dias após a semeadura, com duas e três flores por axila, com posições intermediária, ereta e pendente, e ainda corola amarelo-clara, com comprimento de até $2 \mathrm{~cm}$ e estigma posicionado no mesmo nível ou acima das anteras.

Nos grupos G1 e G2, a frutificação se iniciou aos 60 dias após o transplantio, seguindo até 150 dias. Os frutos eram de coloração vermelha e laranja pálido, pendentes, com comprimento variando de 1 a $2 \mathrm{~cm}$ e a largura até $2,5 \mathrm{~cm}$, massa variando de 2 a $4 \mathrm{~g}$, com paredes com espessura de 3 a $4 \mathrm{~mm}$, com ápice afundado. Foi observada corrugação leve ou intermediária na secção transversal, além de dois e três lóculos. Os frutos foram de intermediários a persistentes em relação ao pedúnculo. $\mathrm{O}$ aroma foi classificado como baixo e a pungência variável, de baixa a média, de acordo com a tabela de descritores e análise sensorial.

No terceiro grupo (G3) estão incluídas as pimentas $C$. chinense do morfotipo curabiá, representadas pelos acessos CDJ01, ATN04, ATN02 e MA46. Todos os acessos tinham caule cilíndrico de coloração verde com presença de antocianina nodal, exceto o acesso ATN02 com coloração violeta. A floração iniciou entre 61 e 90 dias após a semeadura, com mais de três flores por axila, com posição pendente no acesso CDJ01 e ereta nos demais acessos. Os acessos se 
Tabela 2. Frequência de ocorrência de fenótipos de pimenta do gênero Capsicum (frequency of occurrence of Capsicum pepper phenotypes). Manaus, UFAM, 2013.

\begin{tabular}{|c|c|c|c|c|c|c|}
\hline \multirow{2}{*}{$\begin{array}{l}\text { Característica } \\
\text { Cor do caule }\end{array}$} & \multicolumn{6}{|c|}{ Frequência de ocorrência (\%) } \\
\hline & Verde (80) & Verde $\mathrm{c} /$ estrias violetas $(17,5)$ & Violeta $(2,5)$ & - & - & - \\
\hline Altura $(\mathrm{cm})$ & $<25(0,0)$ & $25-45(22,5)$ & $46-65(60)$ & $66-85(5)$ & $>85(12,5)$ & - \\
\hline Número de flores/axila & Uma e duas $(42,5)$ & Uma, duas e três (5) & Duas $(42,5)$ & Três ou mais (5) & Duas e três (5) & - \\
\hline Cor da corola & Branca (10) & Amarelo esverdeado $(87,5)$ & Outra $(2,5)$ & - & - & - \\
\hline Cor da antera & Amarelo (10) & Azul (10) & Violeta $(77,5)$ & $\begin{array}{c}\text { Amarelo c/ mancha azul } \\
\text { clara }(2,5)\end{array}$ & - & - \\
\hline Dias para frutificação & Até $60(0,0)$ & 61 a $90(85)$ & $91-120(15)$ & - & - & - \\
\hline Cor do fruto maduro & Amarelo-laranja $(2,5)$ & Laranja-pálido $(12,5)$ & Laranja $(7,5)$ & Vermelho (50) & Vermelho escuro (15) & Amarelo $(12,5)$ \\
\hline Forma do fruto & Alongado (25) & Arredondado (35) & Triangular $(17,5)$ & Campanulado (15) & Retangular $(7,5)$ & - \\
\hline Comprimento do fruto $(\mathrm{cm})$ & Até $1(17,5)$ & $>1$ a $2(15)$ & $>2$ a $4(32,5)$ & $>4$ a $8(35)$ & - & - \\
\hline Peso de fruto (g) & Até $1(27,5)$ & $>1$ a $2(10)$ & $>2$ a $4(30)$ & $>4$ a $8(5)$ & $>8$ a $12(27,5)$ & - \\
\hline Largura do fruto $(\mathrm{cm})$ & Até $1(7,5)$ & $>1$ a $2,5(62,5)$ & $>2,5$ a $5(20)$ & $>5$ a $8(10)$ & - & - \\
\hline Pungência & Doce (15) & Baixa (5) & Média (35) & Alta (45) & - & - \\
\hline Superfície do fruto & Liso $(52,5)$ & Semi-rugoso (30) & Rugoso $(17,5)$ & & & \\
\hline Espessura da polpa (mm) & Até $1(2,5)$ & $>1$ a $2(30)$ & $>2$ a $3(67,5)$ & & & \\
\hline Posição dos frutos & Pendente (60) & Ereta (30) & Pendente e intermed. (5) & Intermediária e ereta (5) & & \\
\hline Persistência & Pouco $(7,5)$ & Intermediário (65) & Persistente $(27,5)$ & & & \\
\hline
\end{tabular}

caracterizaram ainda por terem corola branca e amarela-esverdeada, e anteras com coloração variando de azul-clara, amarela com manchas azuis e violeta. O tempo de frutificação no G3 se iniciou aos 60 dias após o transplantio seguindo-se até 80 dias. Os frutos apresentaram coloração laranja (CDJ01), vermelho-claro (ATN04) e vermelho-escuro (ATN0 e MA46), os frutos eretos (ATN02, ATN04 e MA46) e pendentes no acesso CDJ01. O formato foi triangular (ATN04) e retangular com comprimento variando de até $4 \mathrm{~cm}$ e a largura de até $2,5 \mathrm{~cm}$, massa variando de $1 \mathrm{a} 4 \mathrm{~g}$, paredes com espessura de $3 \mathrm{~mm}$, sem pescoço, com ápice e afundado. Os frutos são intermediários a persistentes em relação ao pedúnculo. $\mathrm{O}$ aroma é baixo e a pungência é de média a alta, de acordo com a análise dos frutos a partir das classes apresentadas na Tabela 2 .

O quarto grupo $(\mathrm{G} 4)$ é representado pela espécie $C$. chinense, pelos morfotipos olho de peixe (AP04, TBT01, LA02, LA01, ATN05, BC06, BC10) e curabiá (IRB02, IRB03). Nos dois morfotipos as plantas tinham caule verde. A floração se iniciou no período de 60 a 90 dias após a semeadura, a corola é amarela esverdeada com comprimento de até $1,5 \mathrm{~cm}$, número de flores de duas a três por axila. Nos acessos IRB03 e IRB02 o número variou de mais de três flores. Em ambos morfotipos a posição das flores é ereta e intermediária e estigma se posicionando acima e mesmo nível das anteras com coloração violeta. $\mathrm{Na}$ maioria dos acessos as anteras tinham cor violeta, e no acesso LA02 a cor é amarela. A frutificação iniciou aos 60 dias seguindo até aos 180 dias após o transplantio. Os frutos sempre eretos no morfotipo olho de peixe com coloração variando de laranja, laranja-pálido e vermelho-escuro no estádio de maturação. No morfotipo curabiá os frutos são pendentes de coloração laranja pálido. O comprimento do fruto de até $2 \mathrm{~cm}$ e largura de até $2,5 \mathrm{~cm}$ e massa de até 4 $\mathrm{g}$, parede do fruto variando de 1 a $3 \mathrm{~cm}$ e elevada pungência.

O quinto grupo (G5), compreende a espécie C. baccatum, representada pelo acesso MA03, do morfotipo dedo de moça, que ficou isolado no dendrograma possivelmente pelas características diferenciadas nas flores, como manchas difusas na base dos lóbulos quando comparada às demais espécies. As plantas tinham caule verde e a floração se iniciou no período de 60 a 90 dias após a semeadura, com uma e duas flores por axila, com posições interme- diárias e pendentes. A corola é amarela-esverdeada e branca com manchas amarelas na base dos lobos, com anteras amarelas. A frutificação se iniciou aos 60 dias seguindo até aos 180 dias após o transplantio. Os frutos eram pendentes de coloração vermelho-escuro e formato alongado com comprimento de até 8 $\mathrm{cm}$ e largura de até $2,5 \mathrm{~cm}$, massa de até $8 \mathrm{~g}$, parede do fruto variando de 2 a $3 \mathrm{~cm}$ e persistência intermediária com pungência média.

O sexto grupo (G6) é composto pelos acessos MA20 (pimenta de cheiro) e MA35 (curabiá) da espécie $C$. chinense. Houve similaridade entre esses dois morfotipos, e as características que contribuíram para esse agrupamento foram a presença de antocianina nodal no caule e manchas escuras no fruto imaturo. Os acessos MA20 e MA35 apresentaram floração com início entre 60 a 90 dias após a semeadura, corola branca a amarela-esverdeada com comprimento de até $1,5 \mathrm{~cm}$, duas flores por axila, na posição ereta e intermediária e anteras com coloração violeta. A frutificação iniciou aos 60 dias seguindo até aos 180 dias após o transplantio nos dois acessos. Os frutos foram sempre pendentes no acesso MA20 com coloração vermelha-escuro no estádio maduro e 


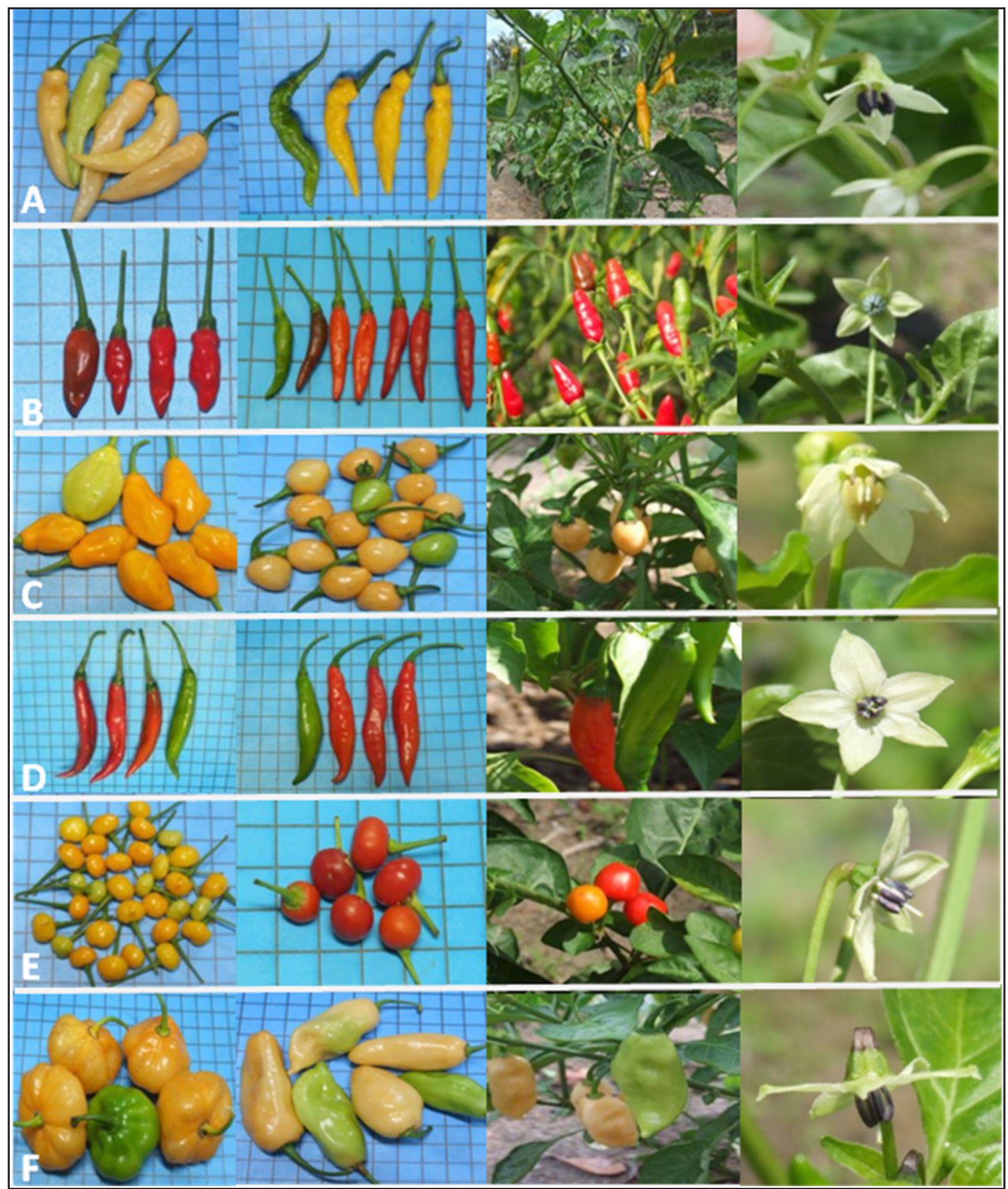

Figura 1. Morfotipos de pimentas (pepper morphotypes): $\mathrm{A}=$ Murupi; $\mathrm{B}=$ Malagueta; $\mathrm{C}=$ Curabiá; $\mathrm{D}=\mathrm{Dedo}$ de moça; $\mathrm{E}=$ Olho de peixe; $\mathrm{F}=$ Pimenta de cheiro. Manaus, UFAM, 2013.

formato arredondado, o comprimento do fruto de $1 \mathrm{a} 2 \mathrm{~cm}$ e largura de até 2 a $4 \mathrm{~cm}$ de largura e massa de 8 a12 g, parede do fruto variando de 2 a $3 \mathrm{~cm}$, e persistentes em relação ao pedicelo.
No acesso MA35 os frutos eram de coloração vermelho escuro e formato triangular, o comprimento do fruto até $4 \mathrm{~cm}$ e largura de até $2,5 \mathrm{~cm}$ e massa de até $4 \mathrm{~g}$, parede do fruto variando de 2 a 3 $\mathrm{cm}$, e pungência classificada como alta.

No sétimo grupo (G7) foram agrupadas duas espécies, $C$. chinense e $C$. frutescens. Esse grupo também reuniu o maior número de acessos, num total 


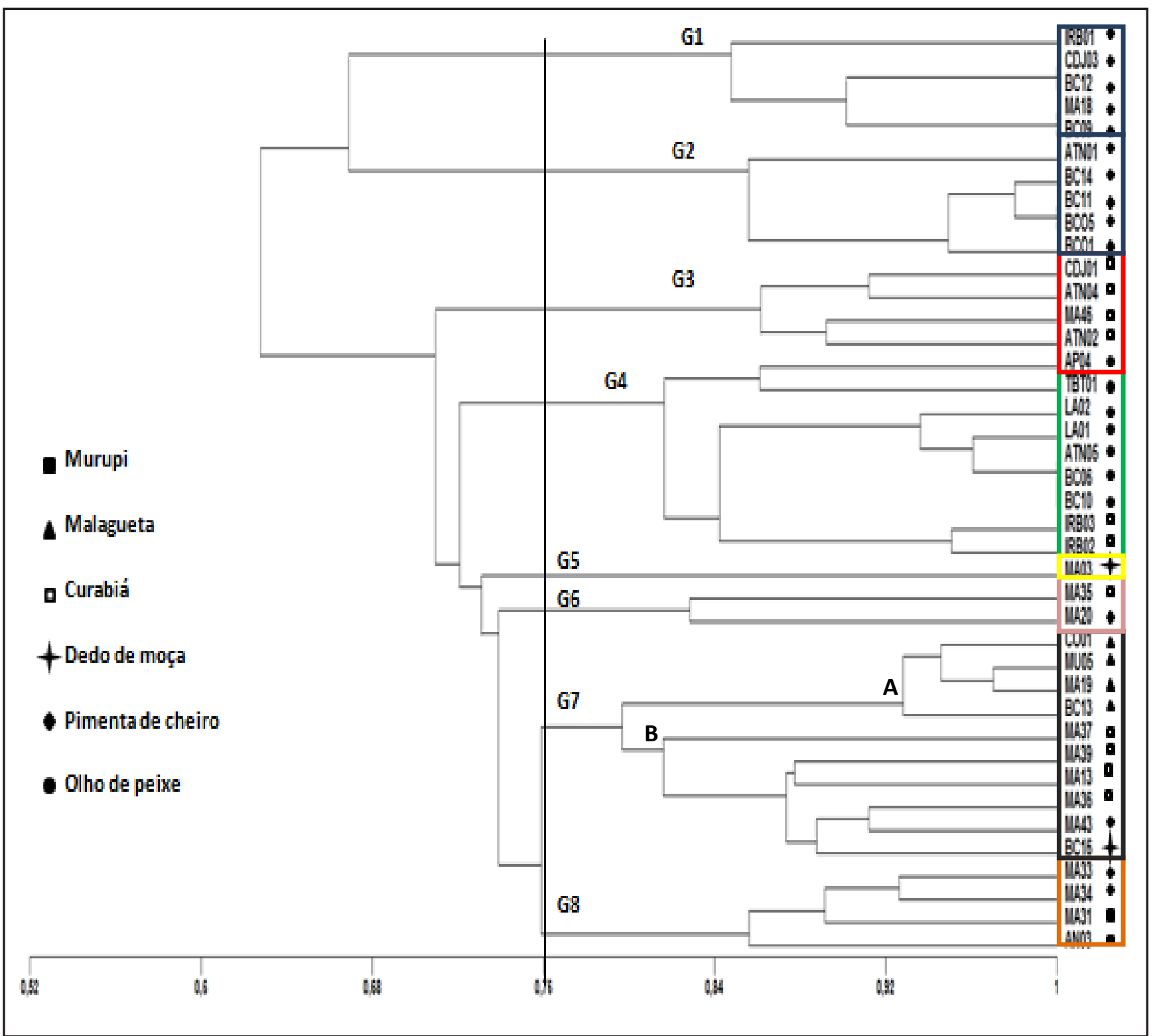

Figura 2. Dendrograma de similaridade genética entre 40 acessos de Capsicum spp., obtido pelo método UPGMA (genetic similarity among 40 Capsicum spp., obtained using the UPGMA method); (G1, G2, G3, G4, G5, G6, G7 e G8= grupos 1, 2, 3, 4, 5, 6, 7 e 8, respectivamente) (G1, G2, G3, G4, G5, G6, G7 and G8= groups 1, 2, 3, 4, 5, 6, 7 and 8, respectively). Manaus, UFAM, 2013.

de dez. O G7 formou dois subgrupos, um (G7A) com o morfotipo malagueta e no outro subgrupo (G7B) estão três morfotipos: pimenta de cheiro, curabiá e dedo de moça.

O subgrupo G7A reuniu exclusivamente acessos da espécie $C$. frutescens (BC13, MU05 e CO01). Neste subgrupo houve uma alta similaridade entre os acessos diferindo apenas no tamanho e superfície dos frutos. As plantas apresentaram caule verde. A floração se iniciou entre 61 e 90 dias após a semeadura, com uma a três flores por axila, com posição ereta. A corola é amarela esverdeada, com anteras de cor azul e azul clara. O início da frutificação foi aos 60 dias, e acima de 80 dias após o transplantio. Os frutos tinham cor vermelha e formato alongado, sendo sempre eretos, e comprimento variando de 1 a $4 \mathrm{~cm}$ e a largura até $1 \mathrm{~cm}$, massa variando de $1 \mathrm{~g}$, com espessura de polpa variando de 1 a $3 \mathrm{~mm}$. Os frutos são persistentes em relação ao pedúnculo e a superfície rugosa no acesso MU05 e lisa nos demais. $\mathrm{O}$ aroma é baixo e a pungência alta. O subgrupo G7B reuniu a espécie $C$. chinense, com os acessos MA37 e MA39 (curabiá), MA13, MA36 e MA43 (pimenta de cheiro) e BC16 (dedo de moça). As plantas tinham caule verde, cilíndrico com presença de antocianina nodal verde com exceção de MA43 cujo caule era achatado, com pubescência esparsa, altura de 45 a 85 $\mathrm{cm}$, e hábito de crescimento intermediário com densidade de ramificação e folhagem densa. A floração iniciou entre 60 a 90 dias após a semeadura, com mais de duas flores por axila, com posições intermediárias e pendentes. A corola variou de branca, amarela e amarela esverdeada com anteras violetas e amarelas. A frutificação iniciou aos 60 


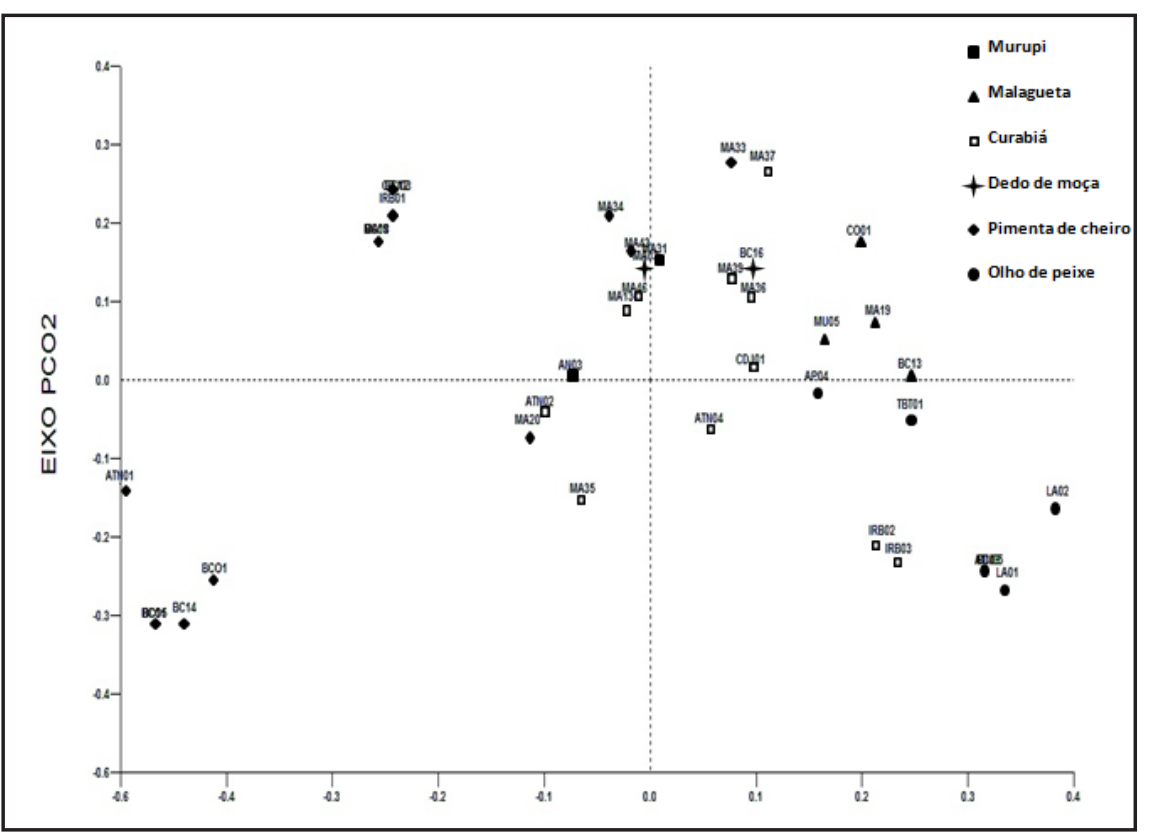

Figura 3. Diagrama de dispersão de 40 acessos de Capsicum ssp. da coleção de acessos da Faculdade de Ciências Agrárias da Universidade Federal do Amazonas (scatter plot of 40 accessions of Capsicum spp. germplasm collection of the Faculdade de Ciências Agrárias da Universidade Federal do Amazonas). Manaus, UFAM, 2013.

dias seguindo até aos 180 dias após o transplantio. Os frutos pendentes com comprimento de até $4 \mathrm{~cm}$ e largura de até $5 \mathrm{~cm}$ e massa de até $4 \mathrm{~g}$, parede do fruto variando de 2 a $3 \mathrm{~cm}$ e persistência intermediária e pungência média.

No oitavo grupo (G8) foram agrupados os morfotipos murupi (MA31, AN03) e pimenta de cheiro (MA34 e MA33) pertencentes a C. chinense. Neste grupo houve uma alta similaridade entre os dois morfotipos, ambos com frutos alongados, porém com cores diferentes, sendo esta característica a que mais contribuiu para esse agrupamento. O caule apresentou cor verde, a floração iniciou aos 61 a 90 dias, com duas a três flores por axila, com posição da flor pendente e intermediária. A cor da corola é branca e coloração da antera violeta. A frutificação iniciou aos 60 dias e persistiu até aos 180 dias após o transplantio. Os frutos foram sempre pendentes com coloração variando no morfotipo murupi, de cor amarela (MA31) e laranja pálido (AN03), no morfotipo pimenta de cheiro. Os dois acessos produziram frutos de cor vermelha no estádio maduro, com comprimento do fruto de até $8 \mathrm{~cm}$ e até $2,5 \mathrm{~cm}$ de largura, massa de até 8 $\mathrm{g}$, parede do fruto variando de $2 \mathrm{a} 3 \mathrm{~cm}$ este agrupamento foi a coloração dos frutos no estádio imaturo e a presença de antocianina nodal violeta no caule, coerentemente com o agrupamento hierárquico pelo método UPGMA com exceção do acesso ATN02. Os acessos do morfotipo malagueta e olho de peixe apresentaram-se apenas em uma área de dispersão cada um. Os dois acessos do morfotipo murupi não se mantiveram muito próximos como no dendrograma, apresentando maior proximidade com os acessos de pimenta de cheiro de formato alongado e campanulado, resultado semelhante ao dendrograma no qual foram agrupados frutos de formato alongados.

De forma geral, o formato dos frutos parece ser o descritor mais efetivo para o agrupamento dos acessos. Em relação à procedência dos acessos, não houve qualquer ligação entre os morfotipos. Estes resultados coincidem com outros encontrados por Luz (2007), e Moura et al. (2010) que também observaram a ausência de correlação entre localização geográfica e distância genética entre acessos de Capsicum. Esta observação pode ser atribuída a uma eficiente e rápida disseminação de sementes, por meio de pássaros, e troca de sementes pelo homem que as transporta livremente entre as diferentes regiões, justificando essa ausência de relação entre procedência e divergência.

A coleção de acessos de Capsicum da UFAM possui uma alta variabilidade, e as características quantitativas e qualitativas analisadas foram capazes de diferenciar as espécies e os morfotipos na coleção. Estes resultados estão de acordo com outros estudos publicados sobre a diversidade genética entre pimentas do gênero Capsicum (Sudré et al., 2006; Luz, 2007; Alves, 2009) demonstrando que os descritores morfológicos são eficientes para avaliação de germoplasma quanto à diversidade genética, empregando métodos de análise multivariada como coeficientes de similaridade genética, métodos de agrupamento e de dispersão gráfica.

As características quantitativas e qualitativas analisadas são capazes de diferenciar os acessos da coleção quanto à similaridade genética. A alta diversidade genética detectada entre os acessos é devida à variedade de cores, 
formatos de frutos, níveis de pungência e arquitetura de plantas observadas nos diferentes morfotipos e pode ser utilizada pelos programas de melhoramento, principalmente para identificação de genitores para a realização de cruzamentos visando desenvolver variedades para o cultivo.

\section{AGRADECIMENTOS}

A FAPEAM pela concessão da bolsa de doutorado à primeira autora e ao Programa de Pós-Graduação em Agronomia Tropical da Universidade Federal do Amazonas, pela oportunidade de realização do curso. Ao CNPq pelo auxílio para a pesquisa.

\section{REFERÊNCIAS}

ALVES SRM. 2009. Caracterização e avaliação de genótipos de pimenta-de-cheiro (Capsicum chinense). Manaus: UFAM. 81p (Dissertação mestrado).

BUTTOW MV; BARBIERI RL; NEITZKE RS; HEIDEN G; CARVALHO FIF. 2010. Diversidade genética entre acessos de pimentas e pimentões da Embrapa Clima Temperado. Ciência Rural \{online\} 40: 1264-1269. Disponivel em http://www.scielo. br/scielo.php?script $=$ sci_arttext\&pid $=$ S0103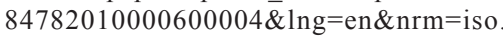 Acessado em 13 de setembro de 2013.

CARVALHO SIC; BIANCHETTI LB; BUSTAMANTE PG; SILVA DB. 2003.
Catálogo de Germoplasma de pimentas $e$ pimentões (Capsicum spp.) da Embrapa Hortaliças. Brasília: Embrapa Hortaliças, (Embrapa Hortaliças, Documentos 49).

FILGUEIRA FAR. 2007. Novo manual de olericultura: agrotecnologia moderna na produção e comercialização de hortaliças. Viçosa: UFV. 402p.

FONSECA RM, LOPES R; BARROS WS; LOPES MTG; FERREIRA FM. 2008. Morphologic characterization and genetic diversity of Capsicum chinense accessions along the upper Rio Negro - Amazonas. Crop Breeding and Applied Biotechnology 8: 187-194.

GOWER JC. 1966. Some distance properties of latent root and vector methods used in multivariate analysis. Biometrika 53: 325-338.

HENZ GP; RIBEIRO CSC. 2008. Pimentas Capsicum: Mercado e comercialização. Brasília: Embrapa Hortaliças.

IPGRI. 1995. Descriptores para Capsicum (Capsicum spp.). IPGRI. Roma 51 p.

LUZ, FJF. 2007. Caracterização morfológica e molecular de acessos de pimenta (Capsicum chinense). Jaboticabal: UNESP. 70p. (Tese doutorado).

MOREIRA GRM; CALIMAN FRB; SILVA DJH; RIBEIRO CSC. 2006. Espécies e variedades de pimenta. Informe Agropecuário 27: 16-29.

MOSCONE EA; SCALDAFERRO MA; GRABIELE M; CECCHINI NM; SÁNCHEZ GARCÍA Y; JARRET R; DAVIÑA JR; DUCASSE DA; BARBOZA GE; EHRENDORFER F. 2007. The evolution of chili peppers (Capsicum, solanaceae): a cytogenetic perspective. Acta Horticulturae 745:137-170.

MOURA MCCL; GONÇALVES LSA; SUDRÉ CP; RODRIGUES R; AMARAL JÚNIOR AT; PEREIRA TNS. 2010. Algoritmo de Gower na estimativa da divergência genética em germoplasma de pimenta. Horticultura Brasileira 28: 155-161.

NEITZKE RS; BARBIERI RL; RODRIGUES WF; CORRÊA IV; CARVALHO FIF. 2010. Dissimilaridade genética entre acessos de pimenta com potencial ornamental. Horticultura Brasileira 28: 47-53.

RÊGO ER; RÊGO MM; MATOS IWF; BARBOSA LA. 2011. Morphological and chemical characterization of fruits of Capsicum spp. accessions. Horticultura Brasileira 29: 364371.

RIBEIRO CSC; CARVALHO SIC; LOPES CA; REIFSCHNEIDER FJB. 2008. Pimentões e pimentas do gênero Capsicum. In: ALBUQUERQUE ACS; SILVA AG (org). Agricultura tropical - quatro décadas de inovações tecnológicas, institucionais e políticas. Brasília: Embrapa Informação Tecnológica v. 1, p.595-608.

RODRÍGUEZ VM; CARTEA ME; PADILLA G; VELASCO P; ORDÁS A. 2005. The nabicol: a horticultural crop in northwestern Spain. Euphytica 142: 237-246.

SUDRÉ CP; CRUZ CD; RODRIGUES R; RIVA EM; AMARAL JÚNIOR AT; SILVA DJH; PEREIRA TNS. 2006. Variáveis multicategóricas na determinação da divergência genética entre acessos de pimenta e pimentão. Horticultura Brasileira 24: 88-93.

SUDRÉ CP; GONÇALVES LSA; RODRIGUES R; RIVA EM; AMARAL JÚNIOR AT; RIVASOUZA EM; BENTO CS. 2010. Genetic variability in domesticated Capsicum spp. as assessed by morphological and agronomic data in mixed statistical analysis. Genetics and Molecular Research 9: 283-294.

TOQUICA SP; RODRÍGUEZ F; MARTINEZ E; DUQUE MC; TOHME J. 2003. Molecular characterization by AFLPs of Capsicum germplasm from the Amazon department in Colombia. Genetic Resources and Crop Evolution 50: 639-647. 